\title{
Correction to: Visible light photocatalysts from low-grade iron ore: the environmentally benign production of magnetite/carbon $\left(\mathrm{Fe}_{3} \mathrm{O}_{4} / \mathrm{C}\right)$ nanocomposites
}

\author{
Muthaimanoj Periyasamy ${ }^{1}$ - Sumanta Sain ${ }^{2}$. Eliza Ghosh ${ }^{3} \cdot$ Kellie J. Jenkinson ${ }^{4}$ - Andrew E. H. Wheatley ${ }^{4}$.

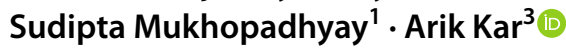

Published online: 19 February 2022

(c) Springer-Verlag GmbH Germany, part of Springer Nature 2022

Correction to: Environmental Science and Pollution Research (2022) 29:6698-6709

https://doi.org/10.1007/s11356-021-15972-2

The Data availability section of this paper contains an erroneous URL.

This section should include the following statement:

Detailed supporting data for this paper are available at the University of Cambridge data repository (see https://doi. org/10.17863/CAM.78490).

Publisher's note Springer Nature remains neutral with regard to jurisdictional claims in published maps and institutional affiliations.

The original article can be found online at https://doi.org/10.1007/ s11356-021-15972-2.

Sudipta Mukhopadhyay

sudiptaiiest@gmail.com

$\triangle$ Arik Kar

akar@chem.iiests.ac.in

1 Department of Mining Engineering, Indian Institute of Engineering Science and Technology, Howrah, Shibpur 711 103, India

2 School of Materials Sciences, Indian Association for the Cultivation of Science, Kolkata, Jadavpur 700 032, India

3 Department of Chemistry, Indian Institute of Engineering Science and Technology, Howrah, Shibpur 711 103, India

4 Department of Chemistry, University of Cambridge, Lensfield Road, Cambridge CB2 1EW, UK 